\title{
BMJ Open The factors influencing the effective early career and rapid transition to a nursing specialty in differing contexts of practice: a modified Delphi consensus study
}

\author{
Diane Chamberlain, ${ }^{1}$ Desley Hegney, ${ }^{2,3}$ Clare Harvey, ${ }^{\oplus}$ Bruce Knight, ${ }^{5}$ \\ Anne Garrahy, ${ }^{6}$ Lily Pei-San Tsai ${ }^{7}$
}

To cite: Chamberlain $\mathrm{D}$, Hegney D, Harvey C, et al. The factors influencing the effective early career and rapid transition to a nursing specialty in differing contexts of practice: a modified Delphi consensus study. BMJ Open 2019;9:e028541. doi:10.1136/ bmjopen-2018-028541

- Prepublication history and additional material for this paper are available online. To view please visit the journal (http:// dx.doi.org/10.1136/bmjopen2018-028541).

Received 16 December 2018 Revised 03 July 2019

Accepted 17 July 2019

Check for updates

(C) Author(s) (or their employer(s)) 2019. Re-use permitted under CC BY-NC. No commercial re-use. See rights and permissions. Published by BMJ.

For numbered affiliations see end of article.

Correspondence to

Professor Diane Chamberlain; di.chamberlain@flinders.edu.au

\section{ABSTRACT}

Objectives This study aimed to test and further develop the 'Early Career and Rapid Transition to a Nursing Specialty' (TRANSPEC) model to a nursing specialty developed from a systematic review. Semi-structured interviews of specialist clinically based nurses and a consensus Delphi study with an expert panel were used to expand and achieve consensus, agreement, reliability and stability of the model.

Design A modified Delphi, two rounds (64 and 52 Likert items) of reiterative online questionnaires and one round as a nominal group technique, was informed by qualitative thematic analysis of semi-structured interviews.

Setting and participants Interviews with 14 specialists clinical practicing registered nurses and a panel of 25 national experts participated in the Delphi study.

Results The interview participants experienced 14 rapid transitions and three were early career transition. The overarching themes from the preliminary model were confirmed and further expanded. These were the self (personal and professional); the transition processes (final and informal); a sense of belonging; and the overarching context of practice over a time continuum. In the Delphi, the highest rating item was 'Specialty work colleagues respect, include, support, and accept specialist nurse on completion of transition processes'. Pre-entry was highlighted as an important time point prior to transition. All items reaching consensus were included in the final model. Cronbach $\alpha$ increased from 0.725 to 0.875 for the final model.

Conclusions The TRANSPEC model is a valid and reliable evidence-based tool for use in the career pathway and development of nursing specialists. Using the Benner model 'Novice to Expert' after the novice incomer phase is achieved, further lifelong learning development will transform the novice specialist over time continuum.

\section{INTRODUCTION}

The shortage of a skilled nursing workforce is a global concern for healthcare delivery. ${ }^{1}$ For example, in Australia it is predicted there will be a shortage of 85000 nurses by 2025 . $^{2}$
Strengths and limitations of this study

- A comprehensive modified Delphi technique study informed by a systematic review and semi-structured interviews achieved consensus and agreement and determined the importance of different elements in an evidence-based specialist transition career pathway.

- The members of the expert panel were a well-selected homogenous group and effectively managed the open and closed questions.

- Anonymity was preserved in the first and third round, with the nominal group discussion allowing for contrasting thoughts and positions.

- The extensive work before the Delphi ensured the questions were clear and relevant. The expert panel could see the expansive view and understood the importance of the study.

- In terms of limitations, the consensus reached in a Delphi may not be a true consensus; it may be a product of specious or manipulated consensus which does not contain the best judgement and may be a compromise position. The extensive work before the Delphi ensured that it was well informed and appropriate to the question.

Internationally, the shortage predicted by 2030 is 7.6 million. ${ }^{3}$ In Australia, current and predicted nursing shortages are attributed to an ageing nursing workforce who are approaching retirement. ${ }^{4}$ This issue is further complicated by a low retention rate of nursing graduates who leave the nursing profession within the first 5 years post-graduation. ${ }^{45}$ Furthermore, issues of chronicity and an ageing population has led to increasing care needs and a redesign of healthcare systems. ${ }^{16-8}$ As a result, acute care systems are more likely to have high acuity patients with shorter stays in hospital ${ }^{9-11}$ and primary 
healthcare systems will have to expand to accommodate specialties within a nursing specialty. ${ }^{12}$

Transition is a concept based on the response to change. ${ }^{13}$ It is a dynamic process necessitating transformation and adjustment occurring over time and requires a reconstruction of self-identity. ${ }^{14-16}$ Previous work, particularly by Benner, ${ }^{17}$ created the novice to expert stages of clinical competence over time: novice, advanced beginner, competent, proficient and expert by adapting the Dreyfus model of professional development and skill acquisition to nursing. Benner's model is suitable as a foundation for the transition to specialty practice as it is based on the premise that expertise is context and scope of practice specific and therefore supports the clinical progression of participants. ${ }^{17}$ Historically, as in Benner's model, the transition to specialist practice has been applied to experienced nurses who have years of experience seen to be necessary before being acknowledged as a specialist. Increasingly health services, however, are recruiting newly graduated registered nurses directly from completion of their programme into nursing specialties. Nursing specialists area of clinical expertise varies. It may be in a population (eg, paediatrics ${ }^{18} /$ neonatal, ${ }^{19-21}$ older person, women's health); a setting (eg, critical/intensive care, ${ }^{22} 23$ emergency room, ${ }^{24-26}$ rural or remote); a disease or medical sub-specialty (eg, diabetes, oncology); a type of care (eg, psychiatric, ${ }^{27}$ rehabilitation); or a type of health problem (eg, pain, wounds, stress). Expert specialists nurses are therefore seen to be highly skilled or knowledgeable within a specific sub-discipline within the nursing discipline. ${ }^{28}$ Specialist transition programmes provide the knowledge and expertise to prepare nurses to provide safe care in response to the specific needs of the specialty area with programmes designed to support the novice through to the expert specialist into advanced specialist practice. Thus, as Benner ${ }^{17}$ identifies, they can build on existing knowledge to refine their practice. Fox et al define transition as a program ${ }^{29}$ as:

The contemporary, post-registration, clinically focused, continuing professional development programmes. These programmes developed for specific cohorts assist the newly graduated or transferred nurse/midwife to acquire further general and specialised knowledge and skills in a logical sequenced supported approach to effectively transition to work expectations.

Using Benner's work as a foundation to rapid specialisation, beginners must undertake a fast-track route to specialty practice, which, in essence, cannot rely on the experiential knowledge that Benner refers to. Rather, they require support through professional development transition programs ${ }^{30} 31$ that assist in identifying steps to specialist practice alongside structured professional coaching and mentorship to support the necessary change of practice and thinking. The use of individualised learning strategies such as self-reflection and debriefing through a problem-based learning approach to practice, working alongside designated mentors, becomes an essential element in the nurse's preparation. In many cases these support programmes are offered both formally and informally from more experienced healthcare specialist practitioners. ${ }^{3032}$ In addition to Fox $e t a l$ s work, ${ }^{29}$ several studies have suggested that novice specialist nurses transitioning may find their new role stressful. ${ }^{33}{ }^{34}$ Due to specialist nursing workforce needs and the predicted loss of experienced nurses through retirement and attrition, there is a need for an efficacious accelerated pathway to specialty practice that is mainly for the newly graduated registered nurse. This is known as an 'early career transition' to specialty practice. ${ }^{35} 36$

According to Levett-Jones and FitzGerald, ${ }^{37}$ transition-to-practice programmes are not exclusive to graduate nurses who are adjusting to the nursing profession but also more experienced nurses as they move from one area of specialty to another. For the purpose of this study, this is defined as 'rapid' transition-the transition of an experienced nurse into specialty practice. ${ }^{38}$ To date, while there has been a large amount of research into the transition of the newly graduated nurse into nursing, ${ }^{39-42}$ there has been little research on the transition of the newly graduated nurse into specialty nursing.

In addition, individual specialties have developed competencies, transition and graduate programmes to meet the needs of each specialty. ${ }^{25}{ }^{43}$ This has resulted in these programmes being developed in silos, with little translation across specialties although there are common elements. ${ }^{44}$ The current and predicted shortages of specialist nurses were the trigger for this study as Queensland Health in Australia sought to develop an evidence-based model to inform both early career and rapid transition to specialty practice.

\section{Aims}

The overall aim of the study was to develop and test the evidence-based model of the "Early Career and Rapid Transition to a Nursing Specialty ${ }^{45}$ (TRANSPEC) to nursing specialties. This was informed by a systematic review and achieved by a Pre-Delphi semi-structured interviews with clinically practising registered nurses who had completed a transition programme/process, and a consensus Delphi study by an expert panel. Using the findings from the systematic review, the objectives of the semi-structured interviews were to: seek to understand the enablers and inhibitors to successful transition at all phases; and identify any gaps in the TRANSPEC model. The objectives of the Delphi were to: investigate from an expert perspective the principles and experience related to early transition; address the gaps in knowledge of the inhibitors and enablers at the pre-entry, incomer and insider phases of transition; achieve consensus on the four concepts (self, transition processes, belonging, context) (Box 1); and achieve agreement, reliability and stability on the TRANSPEC model. 


\section{Box 1: Glossary of terms relating to the TRANSPEC model}

\section{Glossary of Terms}

Context of specialty: a term used to describe the interconnected factors, experiences and opportunities that enable or inhibit a nurse as they progress across the continuum of specialty practice. It is framed by professional and organisational elements. Organisational elements impacting on specialty nursing practice include the geographical location, size and capability of the health service, the community in which the healthcare facility is located and the diversity of healthcare delivered by the health service to that and other communities. ${ }^{73-76}$

Specialty nursing practice: focuses on a distinct area of nursing activity, and is based on a core body of nursing knowledge that is continually developed and refined by practice, research and innovation. Our definition does not include beginning advanced specialty practice.

Transitioning clinician: Clinician transitioning into a specialty context. Transition processes: Any process - formal or informal-that has an impact on the clinician's transition into the role.

Sense of belonging: Feeling of acceptance and inclusion into the team, organisation, specialty.

Pre-entry: The point in the transition before entry where there are factors that impact the clinician prior to entry into the specialty area

Incomer: The point in the transition where the clinician has recently entered into the specialty area and there are factors related to this experience.

Insider: The point in the transition where the clinician feels a sense of belonging, being accepted, respected, included and supported as a member of the specialty team. There are factors related to this experience.

\section{METHODS}

\section{Study design}

\section{Literature review}

The TRANSPEC model was developed from our systematic review of the literature ${ }^{46}$ Four major areas of influence to the transitioning clinician were identified, both early career and rapid transition. These are: the Context of Practice which was the central overarching theme; and the concepts of The Self-professional and personal; the Transitioning Processes - formal and informal; a Sense of Belonging to the team and/or organisation. Enablers and inhibitors within these four areas influenced transition at three significant points: pre-entry; immediately on entry (incomer) and when established as a novice in the specialty (insider). It was possible therefore to map these conceptually (hence the TRANSPEC model emerged). It was also apparent that the overarching theme of the Context of Practice, particularly the geographical location and the specialty, influenced the transition. Thus, it was possible to enclose the phases and concepts within an overarching theme of the Context of Practice. To inform the development of a transition programme, it was possible also to identify enablers, inhibitors or both in each phase and concept.

The preliminary TRANSPEC model was developed from the findings. Refer to figure 1 for the study design, Box 1 for definitions and figure 2 for the preliminary TRANSPEC model. We used this framework to inform the semi-structured interviews and Delphi study.

\section{Specialist nurses' interviews}

Before the Delphi study, semi-structured interviews with specialist clinically practicing registered nurses were conducted to provide insight into the registered nurses' subjective meanings and interpretations of their experiences within a rapid or early career specialisation. We wished to determine if the preliminary TRANSPEC model reflected the reality of an early career and rapid specialisation transition from a specialist registered nurse perspective. The aims were to:

- Formulate detail on strategies (enablers and barriers) that, from their experience, the participants believed would assist/restrict transition.

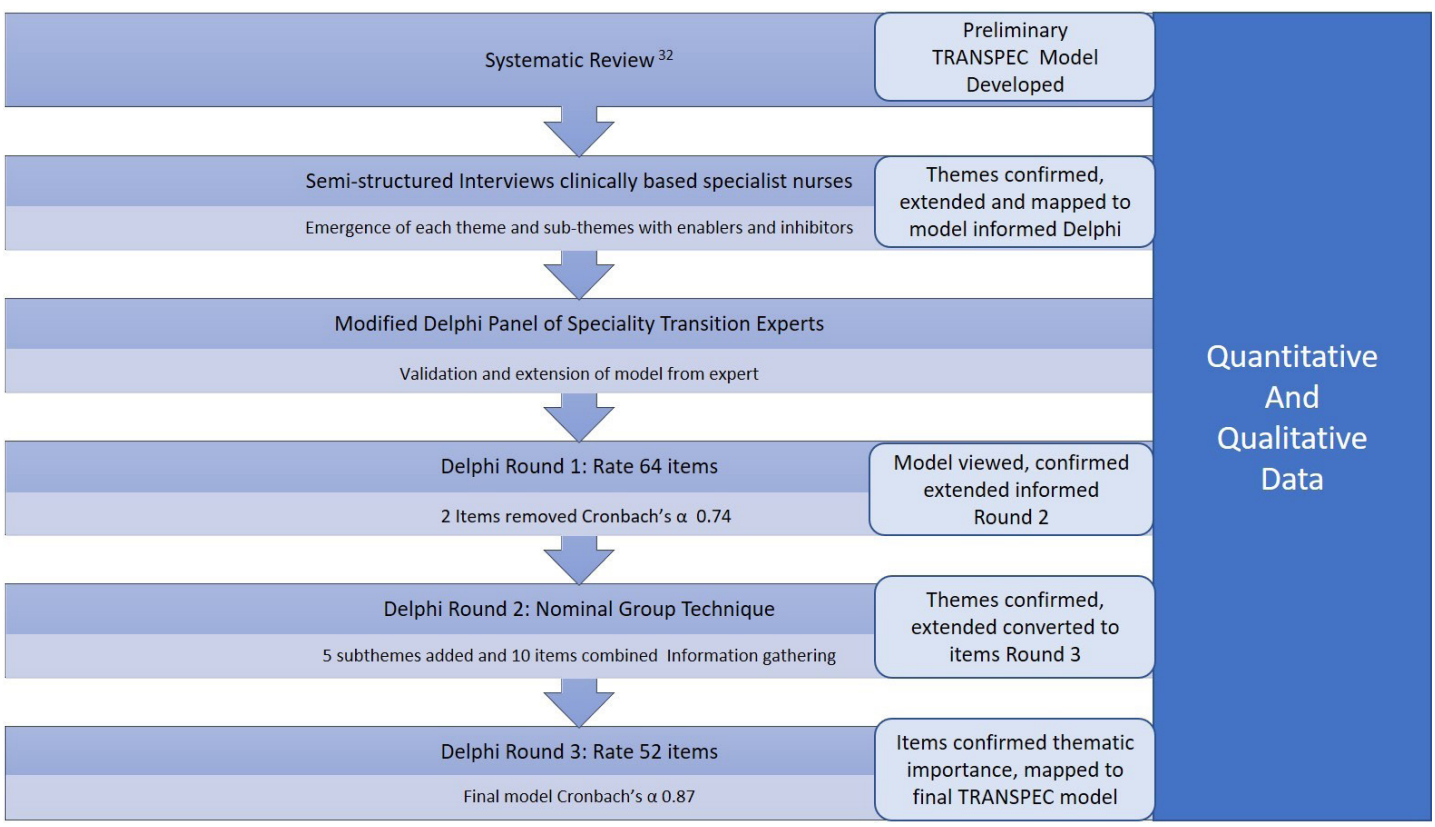

Figure 1 Study design. 


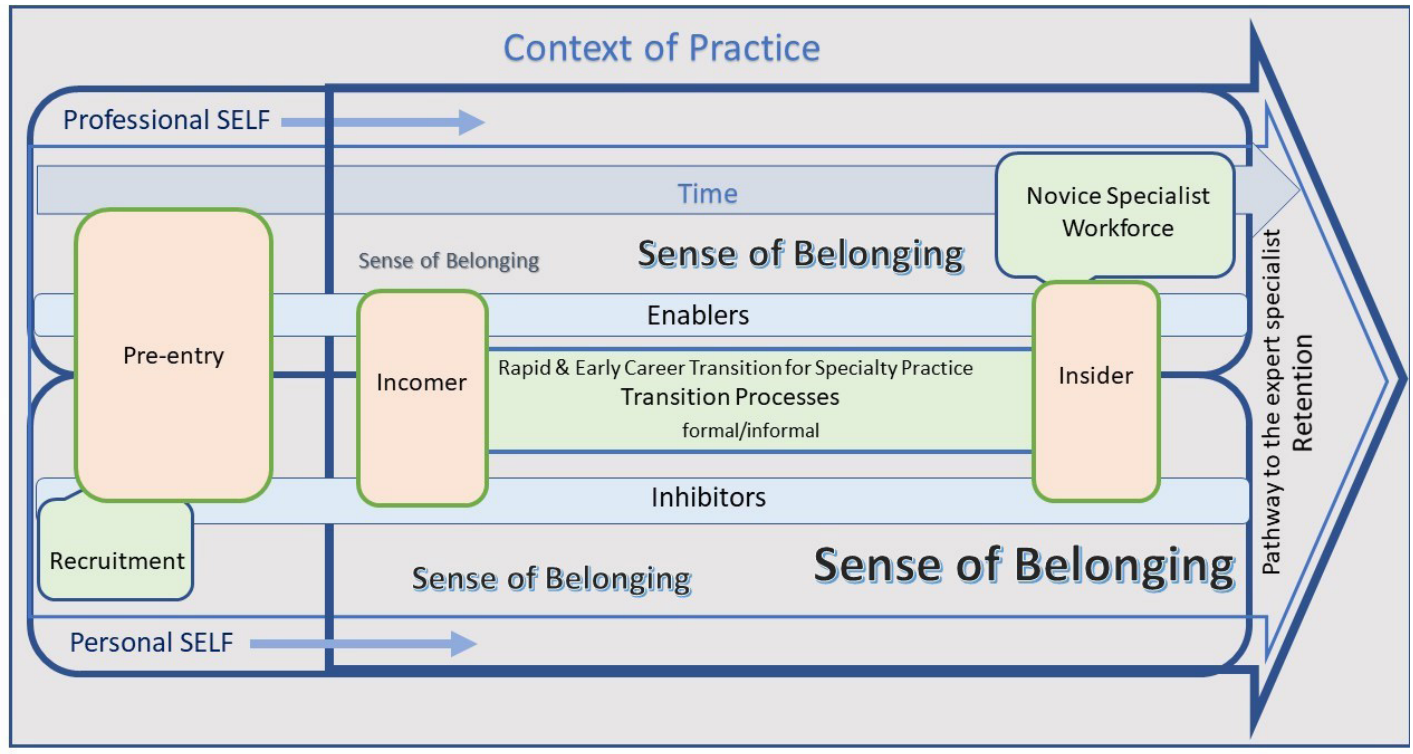

Figure 2 Preliminary TRANSPEC model.

- dentify the gaps in knowledge that informed the TRANSPEC model's transition into policy and practice.

Inclusion criteria were registered nurses, with previous experience of a rapid or early career specialisation in the previous 2 years. Exclusion criteria were registered nurses who had not participated in or did not complete a transition programme and/or who were currently unemployed.

Purposive sampling approaches were used to identify potential participants for the study. The Office of the Chief Nurse and Midwifery, Queensland Health, Brisbane's administrative staff contacted hospitals notifying them of the study and providing information. Registered nurses who met the inclusion criteria and were willing to participate were invited to communicate with the research team. An invitation letter and consent form were sent to eligible candidates that included information about the study, confidentiality and the possibility to withdraw from the study at any time. Once the consent form was received, time and date for a telephone interview were arranged. Participants were advised that the interviews would be digitally recorded for transcription and analysis.

A purposeful sample of 14 registered nurses who met the participant criteria was selected. Four of these nurses had undergone two transitions in the previous 2 years and were asked to discuss both transitions as the programmes differed remarkably from each other. The transition programmes undertaken were: critical care, neonatal, emergency, rural and remote, and perioperative nursing specialties (see online supplementary table 1 ).

A semi-structured interview guide was prepared to ensure that relevant topics were discussed. We ensured that the authors who conducted the analysis were blinded to the preliminary TRANSPEC model to reduce bias. The informants' experiences were highlighted during the interview. Open-ended questions such as: 'Tell us about your experience in your specialty programme at the pre-entry, incomer and insider phases?' and 'How well do you believe the transition process you undertook prepared you for your role (enablers and inhibitors)' and 'What strategies were successful and could be used to improve the transition process (enablers)'. These questions elicited narratives in the registered nurses own words and the interviewers had no prior relationship with the participants. The interviews lasted between 21 and 83 min with an average of 36 min. Following each interview, the recordings were transcribed by a professional transcribing service. The interviews continued until saturation of the data had occurred.

\section{Data analysis}

A thematic analysis framework, as illustrated by Braun and Clarke, ${ }^{47}$ was used considering two levels of codes: semantic and latent. After familiarisation with the transcripts and data, initial codes were developed line by line in a systematic revising fashion, with an independent, iterative and flexible process. Then, codes were collated to form potential themes, and relevant data were gathered for each emerged theme. In the next step, a thematic map of the analysis was generated. The themes were checked with the coded extracts and the entire data set. This step was followed by defining and naming of each theme and their sub-themes as supported by findings. The final step for this model involved exemplary selection in presenting the case of each theme. The semantic or descriptive codes confirmed the TRANSPEC model, and the latent codes using an underlying meaning of content shaped and informed the enablers and inhibitors of early and rapid transition processes to specialty practice. These themes and meanings informed the questionnaire items for the Delphi study. 


\section{Delphi study}

We selected a modified Delphi consensus approach, the essence of the Delphi consensus method is to derive quantitative estimates through the qualitative and mixedmethods assessment of the evidence. ${ }^{48}$ Experts' estimates are aggregated and fed back anonymously to all participants, who then review their initial responses in view of group-wide choices. The technique employs multiple iterations designed to develop a consensus of opinion and is generally applied when examining an area with a scant empirical research base and/or for where there are questions for which there may be no definitive answers. In this study, both situations apply. ${ }^{49}$

\section{Expert panel selection and recruitment}

The Chief Nursing and Midwifery Office administrative staff assisted with the identification of the selection of key stakeholders from national nursing specialist associations, national senior government nurses and nurse executives working in the Queensland Hospital and Health Services. The selection criteria, that is, an extended personal experience of transitioning into a clinical specialty, meant that participants were from specialist clinical nursing practice, nursing specialist organisations or nursing executives of specialist practice areas that were delivering or working towards the provision of transition programme: providing a blend of clinical care delivery, expert specialty practice and senior nursing policy strategists. The national nursing organisations nominated an interested participant from their association who met the inclusion criteria. All of the parties, or their nominee, accepted the invitation to participate. This resulted in a homogenous group of 25 experts as defined by their extended experience of transitioning into a clinical nursing specialty, responding to the invitation. The type of specialty was not a criterion, as we were investigating the principles and experience related to early transition rather than each separate specialty. After consent, those identified were invited to take part.

\section{Patients and public involvement}

There were no patients involved in the study. A public consultation was limited to representatives of specialist nursing organisations and government nursing officers, who were included in the expert panel.

\section{Questionnaire development}

The electronic questionnaires were based on the information derived from the systematic review and the semi-structured interviews and developed using the online survey platform Survey Monkey. The questionnaire was piloted to improve usability and validity with a separate panel of nursing specialist clinicians and qualitative researchers. Changes were made when issues of clarity were raised by this separate panel. Wording and format changes occurred over two iterative cycles before being distributed to the expert panel. Validity was assured by careful survey design and by asking experts to validate the researcher's interpretation and categorisation of the variables and items. ${ }^{50}$ Usability was assured by reports of ease of use during piloting with the design of the interface allowing for more than one subsequent visit for familiarity.

The survey was conducted in two of three rounds from July to September 2018. The objective of the study, the content of the questionnaire and scoring method were explained to the experts, who then scored each item in the questionnaire. They could also add more items in comment boxes if they thought it appropriate.

\section{Delphi round 1}

Experts were presented with the preliminary theoretical model (figure 1) and asked to give their overall view and answer both open-ended and closed importance rating items for enablers and inhibitors within different aspects of the model. Experts were asked to rate each closed item or question using a 5-point Likert scale from 1 (less important) to 5 (very important). The open-ended questions required a comment and narration response. Three reminders were sent by email. Items that achieved consensus, which were stable and displayed convergence, were retained for round 2.

\section{Delphi round 2}

Prior to the second round, the first-round items group mean \pm SD values as well as the newly added views were compiled and sent confidentially to each expert by email. Experts then gave feedback in a face-to-face internet-based meeting room using a nominal group technique. This allowed all to participate without competing for a voice. This was structured on knowledge gaps in the concepts, phases, enablers and inhibitors. A moderator led the open discussion to allow independent and novel thoughts to be gathered without limitation to any components of the model pathway. Similar suggestions were grouped together, where appropriate with a group discussion to clarify and evaluate each idea. With the informed consent of the participant, the discussion was recorded. The resultant agreement on concepts, phases, enablers and inhibitors was aggregated into the model which informed round 3 .

\section{Delphi round 3}

The panel was presented with an updated model and a questionnaire informed by rounds 1 and 2 where both item ratings and qualitative data were transformed into statements with a quantitative rating. The expert was asked to rate items using a 5-point Likert scale with the option of an open-ended response to their choice. Items with a group mean score of more than 3 were retained.

\section{Analysis of Delphi data}

In rounds 1 and 3 the resultant data tables generated by the electronic survey were exported to Stata V.15 software for analysis. Each item response was grouped together and managed as interval data. Group means and SD were used to compare movement between Delphi rounds as a measure of both stability and convergence 
(Greatorex, p 1018)..$^{51}$ The group mean, as a measure of central tendency, 'represents the group opinion of the panel'(Goodsell, p1018). ${ }^{27}$ The SD, as a measure of spread, 'represents the amount of disagreement within the panel' ${ }^{27}$ The median is also reported for comparison to the group mean as an indicator of the direction of the group response. Cronbach's $\alpha$ was used during each round of the Delphi process to determine the internal consistency of survey questions or items. Cronbach's $\alpha$ was also used as a measure of homogeneity for the ratings. Increasing homogeneity was considered to be an indication of consensus among the panellists. An a priori $\alpha$ of $0.7-0.9$ was used to define consensus. ${ }^{52}$

The overall agreement among the experts was determined with the intraclass correlation coefficient (ICC). The ICC is interpreted as follows: $\leq 0.40$, poor consistency or large variation in opinion; $0.41-0.74$, acceptable consistency; and $\geq 0.75$, good consistency. ${ }^{53}$

Consensus and stability were tested by a 2-way random Analysis of variance (ANOVA) with absolute agreement. ANOVA use is based on the normality of the distribution of means rather than the data. As per the central limit theorem, for sample sizes greater than 5 or 10 per group, the means are approximately normally distributed regardless of the original distribution. ${ }^{54}$

Qualitative data were collated from round 2 in the form of a transcribed audio recording of the discussion provided by the participants and from narrative commentary in rounds 1 and 3. Data were analysed using iterative deductive and inductive context analysis. The thematic analysis used a framework approach. ${ }^{55}$

\section{RESULTS}

\section{Specialist nurses' interviews}

The age of participants ranged from 31 to 60 years and the length of time in the nursing profession ranged from 1 to 37 years. They received their rapid or early career specialisation from 11 different early career and rapid transition programmes (see online supplementary table 1). The length of the transition programme ranged from 5 days to 1 year, with the majority of the programmes (particularly those for early career transition) being of 1-year duration. Of 18 different reported transition processes, four participants transitioned to two different specialist areas within the 2-year period. Of 18 transition processes, 15 were a rapid transition and 3 were early career transition. Major areas of transition processes ranged from emergency nursing to rural and remote area nursing (see online supplementary table 1) and were undertaken as a specialist new graduate programme (early career) or as an experienced nurse transitioning into the specialty (rapid). A major destination of the transition process was emergency nursing, followed by intensive/critical care nursing, perioperative nursing, neonatal nursing, and rural and remote area nursing. This reflected the purposive sampling of participants from these specialties. Most participants planned to continue to work in nursing either in Australia or overseas. Through using the framework approach, the major themes of the interviews reflected those themes found in the preliminary TRANSPEC model (figure 1). These major concepts and the overarching theme were: the self (personal and professional); the transition processes (final and informal); a sense of belonging and the overarching context of practice. The phases of transition identified in the transition model could also be identified: pre-entry, incomer and insider as well as the enablers and inhibitors in each of these phases. Refer to online supplementary table 2 for the thematic analysis of the specialist nurse interviews.

\section{Mapping to the TRANSPEC model}

These themes and thematic relationships were mapped to the preliminary TRANSPEC model, confirming provisional themes and concepts and providing new information to the pre-entry phase, confirmed and extended the incomer and insider phase. The sense of belonging sub-theme was mapped and it expanded exponentially inferring its importance in the transition process.

\section{Pre-entry}

Three enablers were identified at the pre-entry phase that enhanced participants to transition into a specialty. Two enablers were related to the professional self (desire to up-skill; more autonomy) and one was related to the personal self (change from the current workplace). In comparison, four inhibitors were identified. Two were related to the professional self (unaware of lack of knowledge and skills; life skills and experience), one to the personal self (stress); and another to a sense of belonging in terms of the context of practice (lack of position for transitioning nurses). Two sub-themes emerged as both an enabler and an inhibitor (preparation; clinical placement during the pre-registration programme) (online supplementary table 2).

\section{Incomer}

Two enablers were identified at this phase that related to formal transition processes (formal learning tool) and personal self (social support through the personal network). In addition, participants identified four inhibitors. Two were related to the professional self (confidence; fear and anxiety), one was related to the formal transitioning programme (lack of completion deadlines) and one inhibitor was related to the culture of workplace leading to a sense of belonging (personality of other staff). In comparison, seven sub-themes emerged as both enablers and inhibitors. Four sub-themes were related to formal transition processes (experiential learning modules embedded in practice; IT or hospital systems; orientation; mentor); two sub-themes were related to culture of workplace which lead to a sense of belonging (staff support; working within teams), and a sub-theme was related to professional self (autonomy) (online supplementary table 2). 


\section{Insider}

At the insider phase, participants highlighted two enablers. These enablers were related to the professional self (understanding the patient flow from one setting to another) and a specific formal transitioning process (primary clinical care manual). Participants identified three inhibitors. These were related to the personal self (isolation) and formal transitioning processes (time frame too short; lack of a completion deadline). Nine sub-themes were identified as both enablers and inhibitors. Three were related to personal self (career advancementleadership; personal experience; confidence), two were related to professional self (transition programme; transferring skills), two were related to formal transitioning processes (accessing education; programme articulation); and two were related to sense of belonging (supported by other staff; culture of the workplace) (online supplementary table 2).

\section{Delphi study \\ Delphi round 1}

In round 1, 16 of 25 invited experts completed the survey (65\% response rate). Those who didn't complete were on personal leave or had left the workforce. Panel members were sourced from paediatric, perioperative, mental health, rural/remote area, emergency, respiratory, intensive care, renal, maternal, child and youth health, primary health and cardiac specialties. The notion of 'Support' was the most frequent $(68 \%)$ keyword regarding recruitment to specialty practice.

The survey contained 64 items or questions. Consensus and internal consistency between survey items were strong except for the inhibitors in the theme of self (professional), which were subsequently removed as they were also listed as an enabler. The highest rating item in enablers for the specialty career pathway was in the category of a sense of belonging, [pre-entry and incomer] 'the role adequately funded' (group mean=4.81), and sense of belonging, [pre-entry and incomer] 'Supported (by specialty work colleagues)' (group mean=4.81), and transition processes formal, [pre-entry and incomer] 'supervision appropriate' (group mean=4.81). The highest rating inhibitors were in the category of self, professional, [pre-entry] 'lack of available positions in the programme' (group mean=4.38), and transition processes-formal [pre-entry and incomer] 'programme under-resourced' (group mean=4.63), and 'insufficient orientation' (group mean=4.50). Online supplementary table 3A, B, C, D shows the group mean rating, SD, median and Cronbach's $\alpha$ for enablers and inhibitors of the themes of self professional (online supplementary table $3 \mathrm{~A}$ ) and personal (online supplementary table $3 \mathrm{~B}$ ), transitioning process (formal and informal) (online supplementary table $3 \mathrm{C}$ ) and sense of belonging to the specialty (online supplementary table 3D), in the categories of pre-entry, incomer and insider.

Agreement between panel experts was strong with the strongest agreement in the theme of self (personal) in the transition category of insider ( (ICC 0.903 (95\% CI: 0.806 to 0.961$), \mathrm{F}(15,90)=9.841, \mathrm{p}<0.001))$. Online supplementary table 4 shows the ICC and F statistic for consistency agreement between experts. The total Cronbach's $\alpha$ for round 1 model was 0.725 .

\section{Delphi round 2}

The nominal group technique feedback meeting consisted of nine experts who were available for the negotiated meeting time derived from an attendance poll from the expert participant group, for 2 hours duration.

After feedback, additional sub-themes were included in the model and theoretical framework. These included strategic measures, where one expert stated:

We have transition pathways within our organisation. It [is] essential to have a transition pathway that matches with career pathways

Further, the theme transition processes was expanded to include sub-themes of 'Education Transformation Activity', 'Workplace Organisation Transformation' and 'Professional Development and Support'. An expert stated (inhibitor under the sub-theme of 'support') that:

If they don't have peers ... then that can set them back in transition. If they don't work with a peer, which often doesn't happen in (the specialty), then they tend to get lost.

Online supplementary table 5 details the nominal group technique thematic analysis and the focus of the theme development for round 3 .

\section{Delphi round 3}

The survey was completed by the same 16 experts as round 1 and contained 52 items. Online supplementary table 6 shows the group mean rating, SD, median and Cronbach's $\alpha$ for the themes of strategic measures, self (personal and professional), transitioning process (formal and informal) including professional development transformation activity, support transformation activity, workplace organisation transformation activity, professional development transformation activity, leading to a sense of belonging to the specialty in the categories of pre-entry, incomer and insider. The highest rating item was in the category of transition process(specialist workforce retention activity), 'Specialty work colleagues respect, include, support, and accept specialist nurse on completion of transition processes' (ICC 0.853 (CI 95\%: -0.740 to 0.992 ) $\mathrm{F}(15,30)=8.82$, $\mathrm{p}>0.001$.).

After the three rounds, the agreement between panel members remained strong (online supplementary table 7) with agreement across all items in the questionnaire reaching significance. The Cronbach's $\alpha$ for the final model had increased to 0.875. All items reaching consensus were included in the final TRANSPEC model (figure 2). 


\section{Formation of the final TRANSPEC model}

The final TRANSPEC model (figure 3) was based on the preliminary model of a rapid and early career nursing specialty transition and then was mapped with our new, confirmed and agreed findings. Time as a continuum featured strongly in both interviews and expert panel ratings and response, so we continued this feature from the preliminary model figure but enhanced it and mapped the new and predominant themes and elements from our investigation across this time continuum, within the 'context of practice'. We increased the requirements outlined at pre-entry phase, this being new knowledge that included pre-entry strategic measures and framed within an expanded knowledge of the personal and professional self. Transition processes, formal and informal were at the time point of the incomer phase and continued through to the time point of insider. Although formal processes are a familiar part of transition programmes, we were able to expand the knowledge of 'Support', especially peer support, and classified mentoring into the personal and professional self, reinforcing the continuum of the personal and professional self as essential elements of the model and depicted by the arrows. Workplace organisation processes featured strongly, again with the personal and professional self. The safety and quality aspects of the workplace organisation featured in line with contemporary organisational best practice as did 'lifelong learning' grounded in experiential learning and capability. The incomer and insider phase over time developed the novice specialist workforce with the transition processes as depicted in the model. The dominance of the 'sense of belonging' found in the preliminary model was confirmed undoubtably in our investigation. Although some theories point to the function of belonging within more general theories of human motivation, ${ }^{56}$ Baumeister and Leary ${ }^{57}$ define sense of belonging as being the extent to which individuals feel personally accepted, respected, included and supported by others in their social environment. Sense of belonging, therefore, is a connectedness with the workplace. The belonging hypothesis suggests that people with experience in success in beginning and sustaining relationships with others and consequently meet their belonging needs are likely to experience a sense of connected with others and well-being in their workplace. Previous nursing research ${ }^{58}$ has established the critical importance of a sense of belonging. Therefore, not until the transitioning novice specialist nurse has a sense of belonging to the specialty, the workplace and the organisation will a pathway to further expertise and retention be successful, and is the main emphasis of our model. These elements have been portrayed and placed in the model featured as figure 3 .

\section{DISCUSSION}

The TRANSPEC model (see figure 3) brings new knowledge to the nursing specialty transition in that it acknowledges the importance of the pre-entry phase, which has not been a focus previously. ${ }^{46} 59$ It also acknowledges that recruitment and retention into specialty nursing practice involve both the professional and personal self. The importance of personal well-being is increasingly being recognised, particularly its effects on quality patient care and patient safety as well as recruitment and retention of the workforce. ${ }^{60}$

Traditionally, it has been assumed that transitioning processes will commence when a workplace receives a transitioning nurse. Recently, early career transitioning programmes/processes have been introduced in response to the current and expected shortages in specialty areas

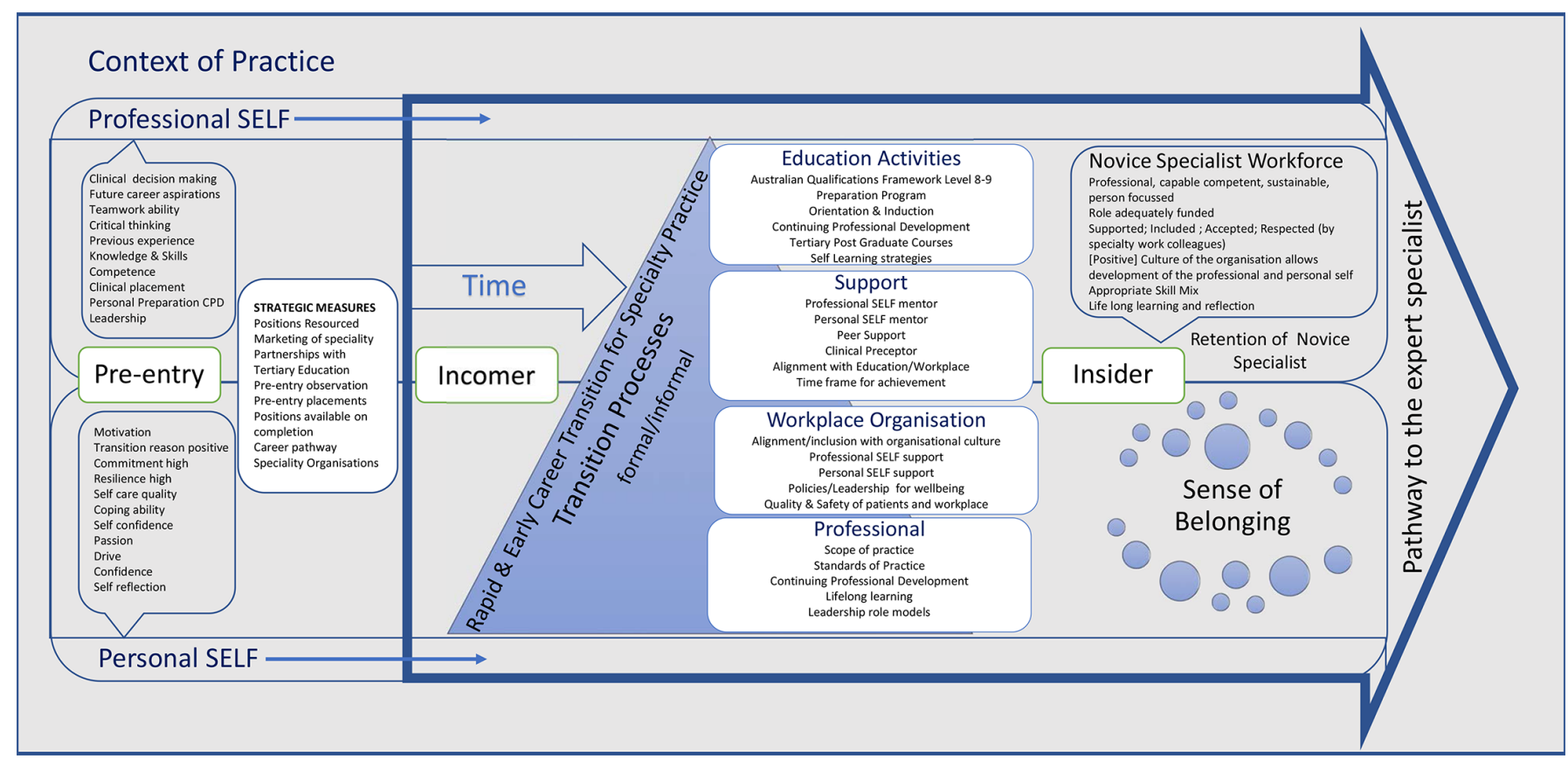

Figure 3 Final TRANSPEC model. 
of nursing. This is because traditional specialisation processes, where nurses are expected to complete several years of clinical experience before commencing specialty practice, do not meet current workforce needs.

It is apparent that the current early career and rapid specialist transition programmes have not been based on evidence that provides both the policy maker and individual workplaces with a pathway to ensure effective recruitment and retention. ${ }^{61}$ Aspects such as additional infrastructure support, supernumerary time, targeted transition processes, personal and professional support processes are required in the recruitment (pre-entry), incomer and insider (retention) phases. The data from these interviews suggest that some early career and rapid transition nurses were expected to 'hit the ground running' on arrival.

Strategic pathways have emerged as a new theme in contrast to previous scholarly work, although some work on the 'transition to specialty practice programme' relate to recruitment as a strategic measure..$^{25}$ The issues of 'pre-entry' have remained in historical government reports as recommendations with little evidence that these have been addressed successfully possibly due to funding limitations and conflicting priorities. ${ }^{62} 63$ 'The re-emergence of 'strategic measures' as a recommendation in our work underlines the importance of these executive level processes for the success of an early and rapid transition to a nursing specialty career pathway.

The need for transition programmes to be designed to enable nurses to build on their previous knowledge and skills in a supportive environment is evident. It is apparent that a 'one size fits all' transition programme does not meet the specific professional needs of transitioning nurses. Strategies to support recruitment into specialty to transition programmes have not been implemented and the data suggest there is a lack of any formalised transition programme for either early career or rapid transition.

The notion of self in both the professional and personal categories was highlighted as important at all phases. In particular, possessing leadership skills were important factors of the professional self. Here, leadership is seen as a process whereby individual differences influence a group of individuals to achieve a common goal rather than a personal trait or characteristics of an individual. ${ }^{64}$ In a contemporary definition and application, it recognises an interactive nonlinear fluid relationship as a process that is able to respond to an ever-changing healthcare environment, including organisational expectations and changes to local and national policy. As such this concept of leadership, both at clinical and executive levels, provides an important contribution to the success of the TRANSPEC. ${ }^{65}$ Al-Dossary and colleagues ${ }^{66}$ support this finding and state that clinical leadership, which is often not recognised and focuses on patients and healthcare teams, is as important as nurse executive leadership in transition programmes.

The 'personal self' in our model features in significant concepts such as motivation, resilience, self-confidence, and self-care ability. Supportive work environments positively impact on the 'personal self' and are an undervalued feature of success and retention. The concept of the personal self consists of personal attributes which may be learnt if not pre-determined ${ }^{67}$ Of note, in this study is the appreciation of 'support' in the recruitment phase of a successful specialty career pathway and as such should be respected. Faraz ${ }^{68}$ also confirms that early mentorship support during a postgraduate fellowship programme made novice nurse practitioners feel supported and gave them confidence in developing their clinical skills.

Support transformation activities were illustrated by adequate time allowance for transition, peer support and clinical preceptor support. Two strong factors of workplace organisation transformation activity were the priority on the quality of processes and safety of patients, clients and workforce as well as workplace organisational leadership and policies that enhance specialty nurse well-being.

The sense of belonging was vital to retention, that is, colleagues and the organisation needed to respect, include, support and accept specialist novice nurses at all phases, but particularly on completion of the transition process. The sense of belonging is not a new finding as exampled in current literature, ${ }^{59}$ 69-71 but our findings emphasise that it starts from pre-entry right through the transition process and is so essential to the retention of specialty nurses.

In addition, at the end of the incomer phase, recognition by nursing specialties of the transition as part of the experiential learning that enhances continuing lifelong learning of the specialist nurse was a key attribute for specialty nurses. A previous 'universal, collaborative and dynamic model' of specialist and advanced nursing and midwifery practice supports that lifelong learning embraces capability in experiential learning as a concept that ensures continued lifelong learning. ${ }^{72}$ Benner's novice to expert model is also grounded on the importance of experiential learning which our work is placed and extends. ${ }^{17}$ Our model confirms the importance of experiential learning and capability to continued successful lifelong learning.

\section{Pathways development}

We believe the TRANSPEC model (see figure 3) provides an evidence-based tool for successful early career and rapid transition to specialty. Beyond the insider phase, transitioning nurses then develop towards the expert specialist as described in Benner's model. ${ }^{11}$ This is the beginning of their specialist nursing career.

The TRANSPEC model will assist in pathways development and programme development for early and rapid transition of nurses. The panel agreed that a standardised programme should be designed using the outcomes of this study as a guide and that individual programmes should be developed using the model. This will ensure consistency of programmes across Australia. 


\section{Recommendations for the career pathway}

This study adds to current knowledge by highlighting the concepts, phases and context of practice and the enablers and inhibitors that are specific to each phase of transition. Some of these attributes are specific to the context of practice such as geographical region and specialty. This study demonstrated that these attributes influence the transition process of nurses and transition programmes needed to consider these factors, which will contribute towards novice specialty nurse retention at the end of the transition.

\section{CONCLUSION}

This study, which involved three data analysis and collection points: systematic review and the development of the draft TRANSPEC model (figure 2), individual interviews with specialty clinically practising nurses and the modified Delphi technique with an expert panel over three rounds, has highlighted and prioritised and discovered new and previously unexposed themes, concepts, phases, enablers and inhibitors. In combination they give a contemporary and evidence base on which the TRANSPEC model has been developed (figure 2) and evaluated (figure 3). Once the transitioning nurse has moved through the TRANSPEC model, they are seen to be a novice in the specialty. Further educational, experiential and lifelong learning development will transform the novice specialist through the Benner's model of 'novice to expert' over the time continuum.

\section{Author affiliations}

${ }^{1}$ College of Nursing and Health Sciences, Flinders University, Adelaide, South Australia, Australia

${ }^{2}$ Research Division, Central Queensland University, Brisbane, Queensland, Australia ${ }^{3}$ School of Nursing, University of Adelaide, Adelaide, South Australia, Australia ${ }^{4}$ School of Nursing, Midwifery and Social Sciences, Central Queensland University, Mackay, Queensland, Australia

${ }^{5}$ School of Education and the Arts, Central Queensland University, Townsville, Queensland, Australia

${ }^{6}$ Department of Health, Queensland Government, Brisbane, Queensland, Australia ${ }^{7}$ School of Nursing, Midwifery and Social Sciences, Central Queensland University, Brisbane, Queensland, Australia

Acknowledgements We wish to acknowledge the work of Dr Lisa Wirihana, formally of the School of Nursing, Midwifery and Social Sciences for her work in Phase 2 of the study where she assisted with participant interviews and data interpretation.

Contributorship statement $\mathrm{DH}$ conceived and designed the study with the support of all authors. DH and LP-ST undertook the interviews and data analysis of the interviews. DC conducted the Delphi study and drafted the manuscript and incorporated the revisions between authors (DH, CH, BK, AG, LP-ST). DC and LP-ST edited all versions prior to final versions. DC designed the model artwork. All authors (DC, DH, CH, BK, AG, LP-ST) read and approved the final manuscript.

Funding The study was funded by the Office of the Chief Nurse and Midwifery Officer, Queensland Health, Brisbane, Australia, grant number RSH/4665.

Competing interests None declared.

Patient consent for publication Not required.

Ethics approval The study was approved by the Central Queensland University Human Research Ethics Committee (0000020980).

Provenance and peer review Not commissioned; externally peer reviewed.
Data availability statement Data are available upon reasonable request.

Open access This is an open access article distributed in accordance with the Creative Commons Attribution Non Commercial (CC BY-NC 4.0) license, which permits others to distribute, remix, adapt, build upon this work non-commercially, and license their derivative works on different terms, provided the original work is properly cited, appropriate credit is given, any changes made indicated, and the use is non-commercial. See: http://creativecommons.org/licenses/by-nc/4.0/.

\section{REFERENCES}

1. World Health Organization. Framing the health workforce agenda for the sustainable development goals: biennium report 2016-2017 WHO Health Workforce. Geneva: World Health Organisation, 2017.

2. Australia HW. Australia's future health workforce - Nurses overview report. Canberra: Commonwealth of Australia, 2014.

3. World Health Organization. Global health observatory data: density of nursing and midwifery personnel. Geneva: World Health Organization, 2019.

4. Australian College of Nursing (ACN). Nurses are essential in health and aged care reform. Canberra: ACN, 2016.

5. Hussain A, Rivers PA, Glover SH, et al. Strategies for dealing with future shortages in the nursing workforce: a review. Health Serv Manage Res 2012;25:41-7.

6. Doughty K, Mulvihill P. Digital reablement-a personalised service to reduce admissions and readmissions to hospitals and nursing homes. Journal of Assistive Technologies 2013;7:228-34.

7. Duckett SJ. Health workforce design for the 21 st century. Australian Health Review 2005;29:201-10.

8. Australia HW. Australia's future health Workforce-Nurses detailed. Canberra: Department of Health, 2014.

9. Hegney D, Rees C, Eley R, et al. Perceptions of nursing workloads and contributing factors, and their impact on implicit care rationing: a Queensland, Australia study. Journal of Nursing Management 2019;27:371-80.

10. Ljungblom $M$. Ethics and lean management-a paradox? International Journal of Quality and Service Sciences 2014;6:191-202.

11. Mazzocato $P$, Savage $C$, Brommels $M$, et al. Lean thinking in healthcare: a realist review of the literature. BMJ Quality \& Safety 2010;19:376-82.

12. Campbell J, Dussault G. A universal truth: No health without a workforce. In: Forum report, third global forum on human resources for health, Recife, Brazil. Geneva: Global Health Workforce Alliance and World Health Organization, 2013.

13. Meleis Al. Role insufficiency and role supplementation: a conceptual framework. Nurs Res 1975;24:264-71.

14. Barnes $\mathrm{H}$. Nurse practitioner role transition: a concept analysis. Nurs Forum 2015;50:137-46.

15. Kralik D, Visentin K, van Loon A. Transition: a literature review. J Adv Nurs 2006;55:320-9.

16. MacLellan L, Levett-Jones T, Higgins I. Nurse practitioner role transition: a concept analysis. J Am Assoc Nurse Pract 2015;27:389-97.

17. Benner P. From novice to expert: excellence and power in clinical nursing practice (Commemorative ed). New Jersey: Prentice-Hall, 2001.

18. Halfer D, Graf E, Sullivan C. The organizational impact of a new graduate pediatric nurse mentoring program. Nurs Econ 2008;26:243-9.

19. Bromley P. Using eDelphi to identify capability requisites for postgraduate certificate in neonatal intensive care nursing. $J$ Neonatal Nurs 2015;21:224-36.

20. Bromley P. Capability: how is it recognised in student nurses undertaking postgraduate studies in neonatal intensive care? J Neonatal Nurs 2018;24:142-7.

21. Coughlan LM, Patton D. A qualitative descriptive exploration of the educational and career plans of early career neonatal nurses and midwives: an Irish perspective. Nurse Educ Pract 2018;28:182-8.

22. Castro E, Click E, Douglas S, et al. The professionalism of critical care nurse fellows after completion of the critical care nurse fellowship program. J Nurses Prof Dev 2016;32:87-93.

23. Klingbeil C, Schiffman RF, Ziebert C, et al. Transition of experienced and new graduate nurses to a pediatric hospital. J Nurses Prof Dev 2016;32:198-204.

24. Glynn P, Silva S. Meeting the needs of new graduates in the emergency department: a qualitative study evaluating a new graduate internship program. J Emerg Nurs 2013;39:173-8.

25. Morphet J, Kent B, Plummer V, et al. The effect of Transition to Specialty Practice Programs on Australian emergency nurses' 
professional development, recruitment and retention. Australas Emerg Nurs J 2015;18:204-11.

26. Morphet J, McKenna L, Considine J. The career development year: responding to the emergency nursing shortage in Australia. Australas Emerg Nurs J 2008;11:32-8.

27. Goodsell TL, Colling M, Brown RB, et al. On past and future of community: a pragmatic analysis. The American Sociologist 2011;42:277-87.

28. Dreher HM, Uribe J. Role Theory and the Evolution of Professional Roles in Nursing. In: Dreher HM, Glasgow MES, eds. Dnp role development for doctoral advanced nursing practice. 2nd ed. New York, NY: Springer Publishing Company, 2016: 55-74.

29. Fox R, Booker C, Turbutt A. Framework for lifelong learning for nurses and midwives. Brisbane: Queensland Health, 2018.

30. Morphet J, Plummer V, Kent B, et al. A framework for transition to specialty practice programmes. J Adv Nurs 2017;73:1970-81.

31. Munroe B, Curtis K, Murphy M, et al. A structured framework improves clinical patient assessment and nontechnical skills of early career emergency nurses: a pre-post study using full immersion simulation. J Clin Nurs 2016;25:2262-74.

32. Schwartz L, Wright D, Lavoie-Tremblay M. New nurses' experience of their role within interprofessional health care teams in mental health. Arch Psychiatr Nurs 2011;25:153-63.

33. Gohery P, Meaney T. Nurses' role transition from the clinical ward environment to the critical care environment. Intensive Crit Care Nurs 2013;29:321-8

34. Patterson B, Bayley EW, Burnell K, et al. Orientation to emergency nursing: perceptions of new graduate nurses. $J$ Emerg Nurs 2010;36:203-11.

35. Hutchinson M, Higson M, Cleary M, et al. Nursing expertise: a course of ambiguity and evolution in a concept. Nurs Inq 2016;23:290-304.

36. Kilpatrick K, Tchouaket E, Carter N, et al. Relationship between clinical nurse specialist role implementation, satisfaction, and intent to stay. Clin Nurse Spec 2016;30:159-66.

37. Levett-Jones T, FitzGerald M. A review of graduate nurse transition programs in Australia. Aust J Adv Nurs 2005;23:40-5.

38. Patterson E, Price K, Hegney D. Primary health care and general practice nurses: what is the nexus? Aust $J$ Prim Health 2005;11:47-54

39. Bakon S, Craft J, Wirihana L, et al. An integrative review of graduate transition programmes: developmental considerations for nursing management. Nurse Educ Pract 2018;28:80-5.

40. Fox R, Henderson A, Malko-Nyhan K. 'They survive despite the organizational culture, not because of it': a longitudinal study of new staff perceptions of what constitutes support during the transition to an acute tertiary facility. Int $J$ Nurs Pract 2005;11:193-9.

41. Mills $\mathrm{J}$, Woods $\mathrm{C}$, Harrison $\mathrm{H}$, et al. Retention of early career registered nurses: the influence of self-concept, practice environment and resilience in the first five years post-graduation. $J$ Res Nurs 2017:22:372-85.

42. Stacey G, McGarry J, Aubeeluck A, et al. An integrated educational model for graduate entry nursing cirriculum design. Nurse Educ Today 2014;34:145-9.

43. Spence K, Sinclair L, Morritt ML, et al. Knowledge and learning in speciality practice. J Neonatal Nurs 2016;22:263-76.

44. Joel LA. Advanced practice nursing: essentials for role development. 4th ed. Philadelphia, PA: F.A. Davis Company, 2017

45. Hegney D, Harvey C, Chamberlain D, et al. A systematic review of the factors influencing the effective early career transition to a nursing speciality in differing contexts of practice. International Prospective Register of Systematic Reviews 2018.

46. Hegney D, Chamberlain D, Harvey C, et al. The development of the TRANSPEC model: a systematic review of the factors influencing the effective rapid and early career transition to a nursing speciality in differing contexts of practice. PLOS One 2019;14:e0216121.

47. Braun V, Clarke V. Using thematic analysis in psychology. Qual Res Psychol 2006;3:77-101.

48. Jones J, Hunter D. Consensus methods for medical and health services research. BMJ 1995;311:376-80.

49. Keeney S, Hasson F, McKenna HP. A critical review of the Delphi technique as a research methodology for nursing. Int J Nurs Stud 2001;38:195-200.

50. Keeney S, Mckenna $\mathrm{H}$, Hasson F. The Delphi technique in nursing and health research. John Wiley \& Sons, 2010.
51. Greatorex J, Dexter T. An accessible analytical approach for investigating what happens between the rounds of a Delphi study. $J$ Adv Nurs 2000;32:1016-24.

52. Graham B, Regehr G, Wright JG. Delphi as a method to establish consensus for diagnostic criteria. J Clin Epidemiol 2003;56:1150-6.

53. Müller R, Büttner P. A critical discussion of intraclass correlation coefficients. Stat Med 1994;13:2465-76.

54. Norman G. Likert scales, levels of measurement and the "laws" of statistics. Adv Health Sci Educ Theory Pract 2010;15:625-32.

55. Gale NK, Heath G, Cameron E, et al. Using the framework method for the analysis of qualitative data in multi-disciplinary health research. BMC Med Res Methodol 2013;13:117.

56. Ryan RM, Deci EL. Self-determination theory and the facilitation of intrinsic motivation, social development, and well-being. Am Psychol 2000;55:68-78

57. Baumeister RF, Leary MR. The need to belong: desire for interpersonal attachments as a fundamental human motivation. Psychol Bull 1995;117:497-529.

58. Levett-Jones T, Lathlean J. Belongingness: A prerequisite for nursing students' clinical learning. Nurse education in practice 2008;8:103-11.

59. Harvey C, Hegney D, Sobolewska A, et al. Developing a community nursing and midwifery career pathway - a narrative systematic review. PLOS One 2019;14:e0211160.

60. Cusack L, Smith M, Hegney D, et al. Exploring environmental factors in nursing workplaces that promote psychological resilience: constructing a unified theoretical model. Front Psychol 2016;7:600.

61. Hooper M-E, Browne G, O'Brien AP. Graduate nurses' experiences of mental health services in their first year of practice: an integrative review. Int J Ment Health Nurs 2016;25:286-98.

62. Senate Community Affairs References Committee. The Patient Profession: Time for Action - Report on the inquiry into nursing. Canberra: Senate Printing Unit, 2002.

63. Mason J. Review of Australian government health workforce programs, 2013.

64. Fitzgerald B, Torres A, Robertson J, et al. CANO/ACIO position paper: leadership. Canadian Oncology Nursing Journal/Revue canadienne de soins infirmiers en oncologie 2017;27:88-9.

65. Hafsteinsdóttir TB, van der Zwaag AM, Schuurmans MJ. Leadership mentoring in nursing research, career development and scholarly productivity: a systematic review. Int J Nurs Stud 2017;75:21-34.

66. AL-Dossary R, Kitsantas P, Maddox PJ. The impact of residency programs on new nurse graduates' clinical decision-making and leadership skills: a systematic review. Nurse Educ Today 2014;34:1024-8.

67. Mishra P, McDonald K. Career resilience: an integrated review of the empirical literature. Human Resource Development Review 2017:16:207-34.

68. Faraz A. Novice nurse practitioner workforce transition into primary care: a literature review. West J Nurs Res 2016;38:1531-45.

69. Baumann A, Crea-Arsenio M, Hunsberger M, et al. Work readiness, transition, and integration: the challenge of specialty practice. $J$ Adv Nurs 2019;75:823-33.

70. Calleja P, Adonteng-Kissi B, Romero B. Transition support for new graduate nurses to rural and remote practice: a scoping review. Nurse Educ Today 2019;76:8-20.

71. Moran GM, Nairn S. How does role transition affect the experience of trainee advanced clinical practitioners: qualitative evidence synthesis. J Adv Nurs 2018;74:251-62.

72. O'Connor L, Casey M, Smith R, et al. The universal, collaborative and dynamic model of specialist and advanced nursing and midwifery practice: a way forward? J Clin Nurs 2018;27:e882-94.

73. COAG Health Council. Guidance for national board submission re specialist registration. Canberra: Commonwealth of Australia, 2014

74. Organisations NN. Criteria for Specialities in Nursing/Principles of Credentialling for nurses. Kingston: National Nursing Organisations, 2004

75. Nursing and Midwifery Board of Australia. Code of conduct for nurses. Melbourne: NMBA. Melbourne: Nursing and Midwifery Board of Australia, 2018.

76. Health Q. Transition support programs user guide (adapted for MNHHS context. Brisbane: Queensland Health, 2012. 